\title{
The Effect of Variation Sensitivity Against Time For Magnesium Oxide (MgO) Doped Polyaniline Nanocomposites Influenced By Ammonium Persulfate
}

MANJUNATHA B ( $\nabla$ manjunatha179@gmail.com )

Bheemanna Khandre Institute of Technology https://orcid.org/0000-0001-5948-8475

Rahul Jabnoor

Bheemanna Khandre Institute of Technology

Sangshetty kalyane

Bheemanna Khandre Institute of Technology

Original Research

Keywords: Polyaniline, MgO, XRD, Sensors

Posted Date: February 15th, 2021

DOI: https://doi.org/10.21203/rs.3.rs-194920/v1

License: (c) (i) This work is licensed under a Creative Commons Attribution 4.0 International License.

Read Full License 
The effect of Variation sensitivity against time for Magnesium Oxide $(\mathrm{MgO})$ Doped Polyaniline Nanocomposites influenced by ammonium persulfate

\author{
Manjunatha $B^{1^{*}}$, Rahul Jabnoor ${ }^{2}$, Sangshetty kalyane ${ }^{3}$
}

1,2\&3 Department of Physics Bheemanna Khandre Institute of Technology Bhalki- Karnataka

\title{
*Corresponding author email: manjunatha179@gmail.com
}

\begin{abstract}
Polyaniline and doped polyaniline was prepared by the method of insitu chemical oxidative polymerization with ammonium persulfate as an oxidant agent. The composite polyaniline was mixing the magnesium oxide and polyaniline with the PANI matrix distributions. Polyaniline composite of $\mathrm{MgO}$ characterized like as $\mathrm{x}$-ray diffractometer shows structural properties. The electrical properties of polyaniline and composite polyaniline as a conductivity increases with increase in frequency. The sensor property shows the sensitivity with the help of time obtained the sensitivities values the ranges from 120 to $160 \%$ from these composites in $50 \%$ composite the sensitivity is high.
\end{abstract}

Key words-: Polyaniline, MgO, XRD, Sensors

Abbrevations

PANI Polyaniline

XRD- X-Ray diffraction AC- conductivity

APS -Ammonium persulphate $\quad \mathrm{MgO}-$ Magnesium oxides 


\section{Introduction}

Now a days the interesting research area is polymeric material due to reality of these materials have large potentially device of the sold states. The mainly study conductivities of the polymer is PANI an organic conductivity polymeric confirm the performance mutually a conductors and semiconductors obtain throughout the chemically and electrochemically route [1]. Conductive polymeric materials was conjugate organically chain compound that shows large electrically conducting like to metal since here huge carrier concentration of extensive $\pi$ electron, well-known as polaron, which permit the charging mobility along the strength of character of the polymeric chains. The polymer contains numbers of advantage likes lessweight, flexibilities, less costs. The polymeric conductive materials have much application such as cellular telephones, television sets, displays, solar cells light emitting diodes, ,actuators, sensors, batteries, electromagnetic shield, and microelectronic device Among the conductive polymer, PANI has been of exacting curiosity due to its handy electrically conducting, more absorptions coefficient in the noticeable light, attractive redox properties, good chemical stabilities, relative highly conducting, easy polymerizations,[2-7] Polyaniline (PANI) survive in a different number of form can be different in the chemically and physically property[8-10]. Leucoemeraldines is a completely reduces form and is yellowish colour,nigranilines is blueish colour,protoemeraldines is brownish colour,emeraldines is greenish colour and Pernigranilines is violet colour. A variety of oxidize agent/monomers ratio have been used. Ammonium peroxydisufate is usually used as oxidizing agent. There are quinonoid and benzenoid resonances according to amines and imines structure. Change the ratios of amines to imines, a variety of structure are formed [11-12]. By the oxidizes with HCL, ADC, APS produces the pernigrandline ,Emeraldine and nigraniline in extreme crystalline [13]. The PANI/ MgO nano-composite that have large property like being unscented and the non toxics as well as possessing highly hardenings, superior purities and highly melting points The magnesium oxide may be an add-on advantage in these fields of polymer; in exacting, it may give superior applications while doped to PANI. The property of the magnesium oxides like high hardening and highly melt points can be used as refractory's agent. Little previous information explains the sensitivities and selectivity's in the research of nanostructure PANI with the adding together of different metals oxide [14-15]. Nanostructure metals oxide are promise original material for blends with polymer, due to brilliant mechanically, electrically, thermally and multifunctional properties. Separately from the physical properties of composite magnesium oxides these nanocomposites have shown 
good [16].Sensor instrument is converter measure the physical quantities converts the signal which can be note down the instrument. In case the mercury in a thermometer move 1 centimetre when the temp change by $1{ }^{\circ} \mathrm{C}$, the sensitivity is $1 \mathrm{~cm} /{ }^{\circ} \mathrm{C}$. Sensors that evaluate very little change must have extremely high sensitivity. Sensors also have an force on what they measures.[17]

\section{Materials and methods}

All Chemicals used were analytical reagent (AR) grade. Ammonium persulphate $\left(\left(\mathrm{NH}_{4}\right)_{2} \mathrm{~S}_{2} \mathrm{O}_{8}\right)$, Hydrochloric acid (HCL), , Magnesium Oxide (MgO) were procured from Sigma Aldrich and were used as received.

\section{Synthesis of Polyaniline-MgO Composites}

$0.2 \mathrm{~mol}$ of aniline was dissolved in $2 \mathrm{M} \mathrm{HCl}$ to form aniline hydrochloride. Magnesium Oxide $(\mathrm{MgO})$ is added in the different weight percent to aniline hydrochloride solution with vigorous stirring in order to keep the Magnesium Oxide $(\mathrm{MgO})$ suspended in the solution. To this reaction mixture, $0.2 \mathrm{M}$ of ammonium persulphate $\left[\left(\mathrm{NH}_{4}\right)_{2} \mathrm{~S}_{2} \mathrm{O}_{8}\right]$ which acts as the oxidant was added slowly with continuous stirring for $4-6$ hours at $0-5^{0} \mathrm{C}$. The precipitate powder recovered were vacuum filtered and washed with water and acetone. Finally the resultant precipitate was dried in an oven for 24 hours to achieve a constant weight. In this way, five (5) different polyaniline Magnesium Oxide ( $\mathrm{MgO})$ composites with different wt\% of $\mathrm{MgO}$ have been synthesized.

\section{Result and discussions}

XRD-: XRD patterns of PANI nanocomposite samples were obtained using an advance diffractometer with monochromatic $\mathrm{CuK} \alpha$ radiation $(\lambda=1.54 \mathrm{~A})$ to identify the crystalline nature of the samples.

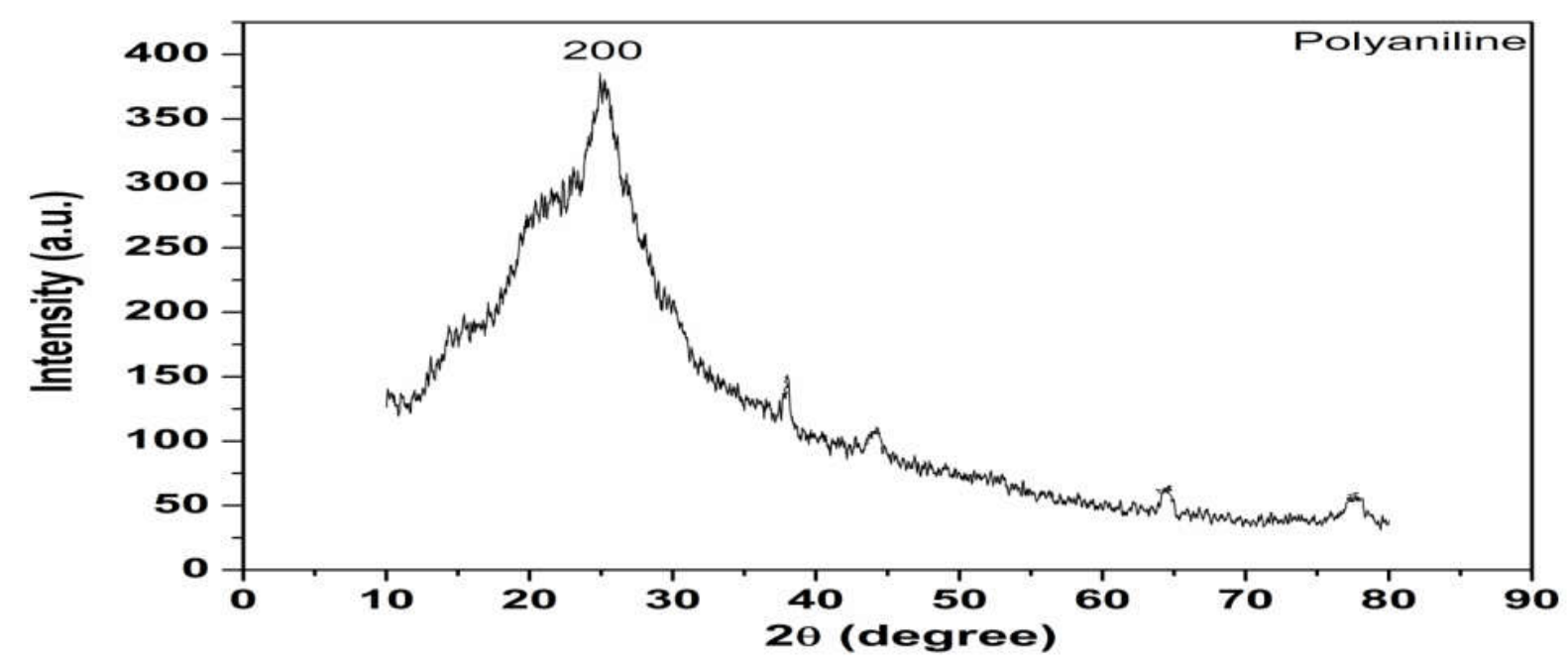


Figure-1: XRD pattern of Pure PANI

Figure-1 is the X-ray diffraction patter of pure polyaniline. Usually polyaniline is amorphous in nature. The broad peak was observed in the $2 \theta$ ranging from $25-27^{\circ}$, which is the main characteristics peak of polyaniline and the broadness of the peak clearly shows the sample is amorphous, indicating that PANI exhibited some degree of crystallinity. .

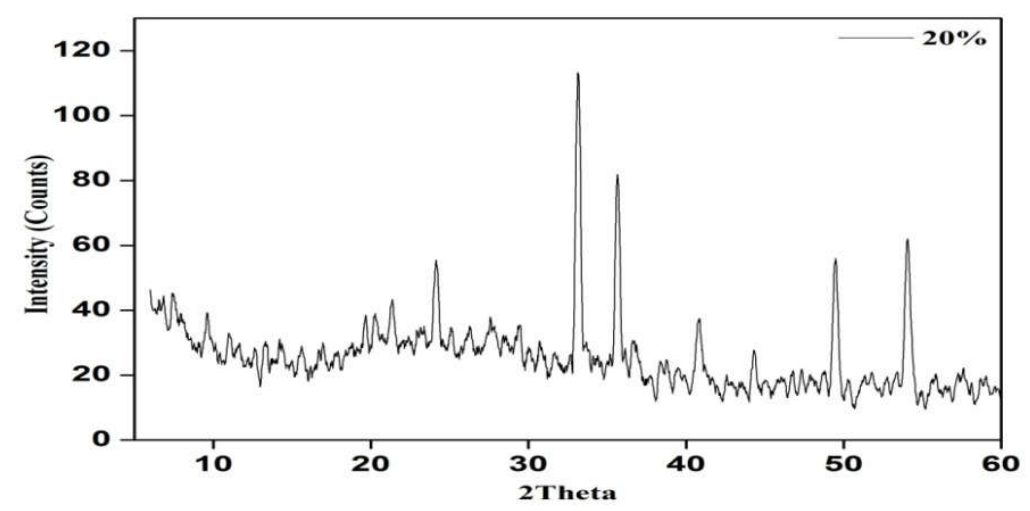

Fig 2: shows the X-ray diffraction pattern of PANI - MgO composite with 20 wt \%

Fig 2 explains the composite pani- $\mathrm{MgO}$. Obtain be able to be indexed to be cubics stature explain the X-ray diffraction outline of Polyaniline - $\mathrm{MgO}$ composite with $20 \mathrm{wt} \%$ of $\mathrm{MgO}$ in polyaniline. The above fig says that crystallinities of compound diminish since shapeless environment of composite pani [18]

\section{ELECTRICALPROPERTIES}

\section{AC-conductivity}

\section{Polyaniline-MgO composites}

The figure 3 shows tells that it is observes the AC conductivities of the all composite leftovers the stable and prove alike performance up to $10^{5} \mathrm{~Hz}$, past this regularity it raise abruptly. And activities are the characteristics of disordering material, and this attributes in variations of distributions of magnesium oxides particle in matrix of the polymeric.. Gasses sensors is a machine to facilitate can modify the attentiveness of an analyte gas into an electronical[19] or electricallly signasl[20]. 


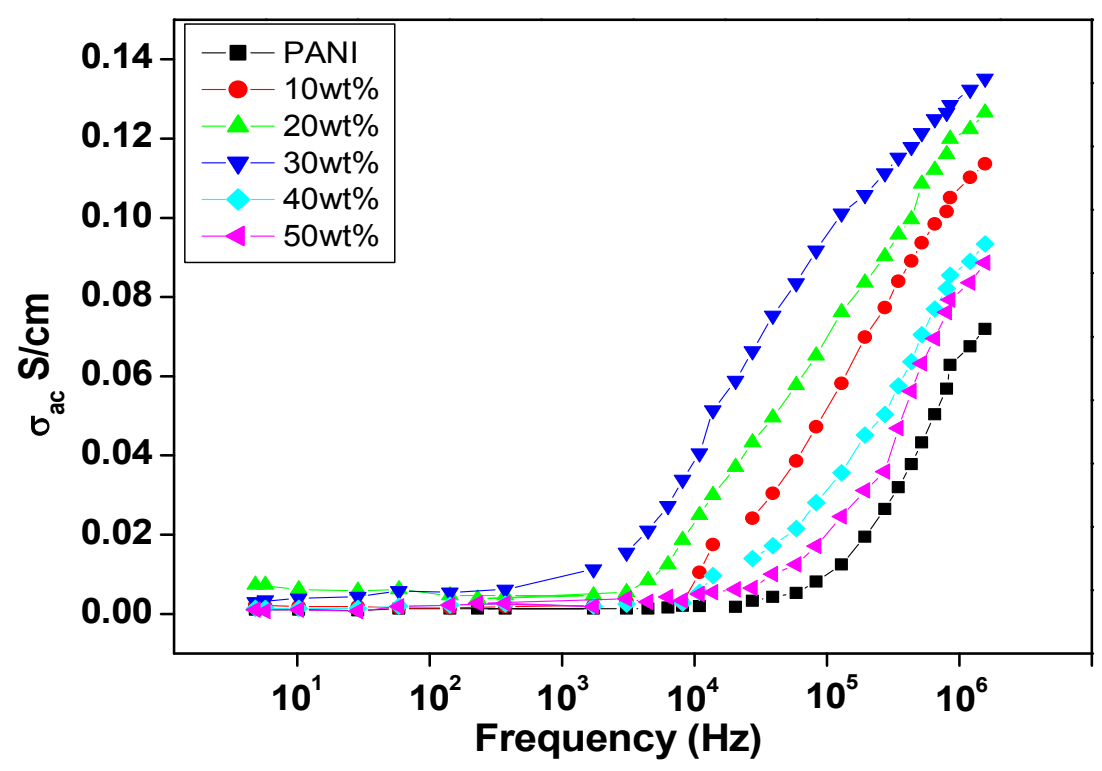

Fig 3: Variation of $\sigma_{\mathrm{ac}}$ as a function of frequency for PANI-MgO

\section{SENSOR STUDIES}

The gassing sensors properties is a like chemically sensors it oerating gaseous phases and also this is significant components device generally recognised as "electrical noses[21]. Fig 4 shows the difference of sensitivities with time for pure Polyaniline. It recorded the sensitivity values the pure PANI sensing range is $27 \%$.

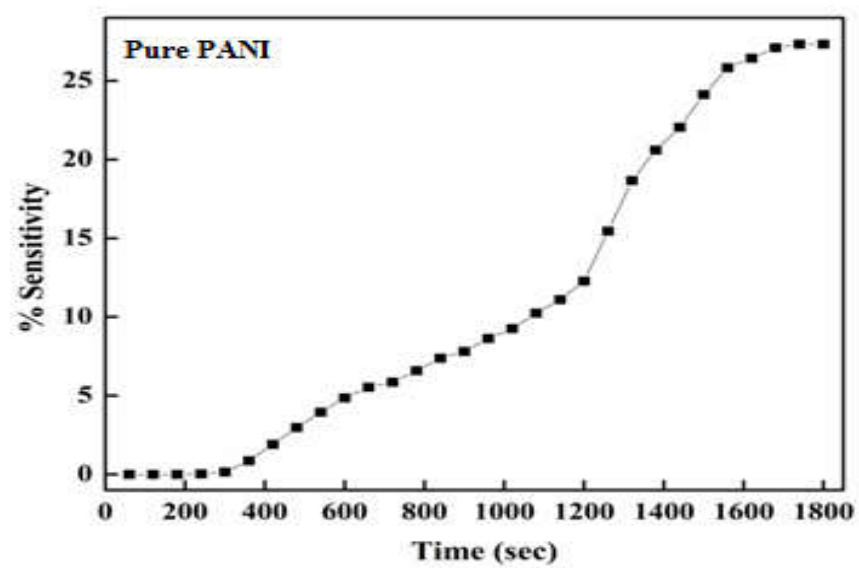

Fig 4: difference of sensitivities versus time for pure PANI

Fig 5 shows the sensitivity against time for PANI-MgO composite its recorded the sensitivities values the ranges from 120 to $160 \%$ obtained from composites 40 and 30 the all different wt percentages compared to $50 \mathrm{wt}$ composite because $50 \mathrm{wt}$ percent composite the sensitivity is high.[22-24]. 


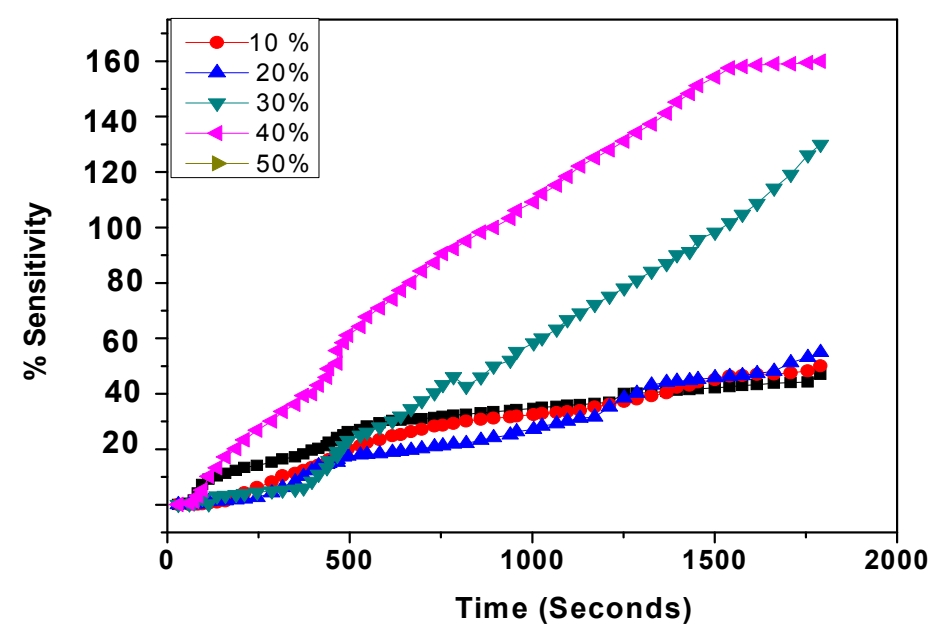

Fig 5 : difference of sensitivities next to time for PANI-MgO

\section{Conclusion}

The PANI and PANI/MgO composites were prepared by chemically oxidative using aniline hydrochloride as a monomer. The XRD studies confirmed the formation of PANI and its composite and it indicates that PANI/ MgO composite have an orderly arrangement of the polymer chain, whereas these PANI nanostructures are slightly crystalline in nature. SEM images helped to draw the conclusion that the doping of $\mathrm{MgO}$ had an effect on PANI morphology, and with increased $\mathrm{MgO}$ content, the composites showed a transformation in morphology from typical granular and nonporous PANI particles. Further these nano composites had also proved beneficial for using Gas sensors have found wide applications in industrial production, environmental monitoring and protection

\section{Conflict of interest}

Each author announce that readily available are no conflict of attention.

\section{REFERENCESS}

[1]. B. Manjunatha \& Arjun N. Shetty \& S. Kaveri \& Sundar S. Mety \& K. C. Anjaneya \& Ramakrishna Reddy \& Sangshetty Kalyane 5 Chemical Mediated 
Synthesis of Polyaniline/Tungstenoxide (PANI/WO3) Nanocomposites and Their Antibacterial Activity Against Clinical Pathogenic Bacteria BioNanoScience BioNanoScience 2020,, 10(1), 73-80

[2]. Ali, M.A.; Saion, E.; Yahya, N.; Kassim, A.; Dahlan, K.M.; Hashim, S. Synthesis of conducting polyaniline nanocomposites by radiation doping. J. Eng. Sci. Technol. 2007, 2, 111-118.

[3]. Reda, S.M.; Al-Ghannam, S.M. Synthesis and electrical properties of polyaniline composite with silver nanoparticles. Adv. Mater. Phys. Chem. 2012, 2, 75-81.

[4]. Chuang, F.-Y.; Yang, S.-M. Cerium dioxide/polyaniline core-shell nanocomposites. J. Colloid Interface Sci. 2008, 320, 194-201.

[5]. Li, L.; Yan, G.; Wu, J.; Yu, X.; Guo, Q. Preparation of polyaniline-metal composite nanospheres by in situ microemulsion polymerization. J. Colloid Interface Sci. 2008, 326, 72-75.

[6]. Wankhede, Y.B.; Kondawar, S.B.; Thakare, S.R.; More, P.S. Synthesis and characterization of silver nanoparticles embedded in polyaniline nanocomposite. Adv. Mater. Lett. 2013, 4, doi:10.5185/amlett.2012.icnano.108.

[7]. Goto, H. A possibility for construction of an iodine cleaning system based on doping for $\pi$-conjugated polymers. Polymers 2011, 3, 875-885.

[8]. A. G. MacDiarmid, Rev. Mod. Phys., 73, No. 3, July 2001

[9]. J. Stejskal, P. Kratochvil, A. D. Jenkins. Polymer 37, 1996, pp- 367.

[10]. D. C. Trivedi. In Handbook of Organic Conductive Molecules and Polymers, H.S. Nalwa (Ed.) 2, Wiley, Chichester (1997), pp. 505-572.

[11]. S. P. Armes and J. F. Miller. Synth. Met. 22, (1988),pp-385-393

[12]. Trivedi, D.C.Indian J. Chem. 33A, (1994), pp-552.

[13]. A.T.Oza, Ph.D. thesis, Indian Institute of science,Bangalore, 1980 
[14]. Zuo, F., Angelopoulos, M., MacDiarmid, A. G., \& Epstein, A. J. (1987). Transport studies of protonated emeraldine polymer: a gran- ular polymeric metal system. Physical Review B, 36(6), 3475.

[15]. Patel, R. G., Solanki, G. K., Prajapati, S. M., \& Oza, A. T. (2005). Kuhn periodicity in oligoanilines and oligoaniline-iodine com- plexes. Molecular Crystals and Liquid Crystals, 442(1), 167-180.

[16]. Green, A. G., \& Woodhead, A. E. (1912). CXVII-aniline-black and allied compounds. Part II. Journal of the Chemical Society, Transactions, 101, 11171123.

[17]. .Synthesis, Characterization and Dielectric Behaviour of Polyaniline/In2O3 Composites G. K. Vinayak, B. Chakradhar Sridhar, Jakeer Hussain, and M.V. N. Ambika Prasad, Journal of Advanced Physics 1 (5) 2016.

[18]. W F Brown, Dielect. Handbook Phy.,) Springer-Veriag, 17 (1956)

[19]. J P Clere, G Girand, J M Laugier and J M Lucky, Adv. Phys.,39 (1990) 191.

[20]. A Esquerrat, F Kremer and G Wagner, Prog. Electromag. Res., (Ed,A.Priou) Elsevier, New York, 6 (1992).

[21]. J G Termau, Mat. Res. Lab., (1988) 1143.

[22]. Z C Kang, Func. Oxide Nanocrys.; Tsinghua University Press: Beijing, (2002).

[23]. P R Somani, A K Viswanath, R C Aiyer and S Radhakrishnan, Novel dye + solid polymer electrolyte material for optical humidity sensing. Actuators B, 80 (2001) 141.

[24]. A Berna, Metal Oxide Sensors for Electronic Noses and Their Application to Food Analysis 10(4) (2010) 3882-3910 

Figures

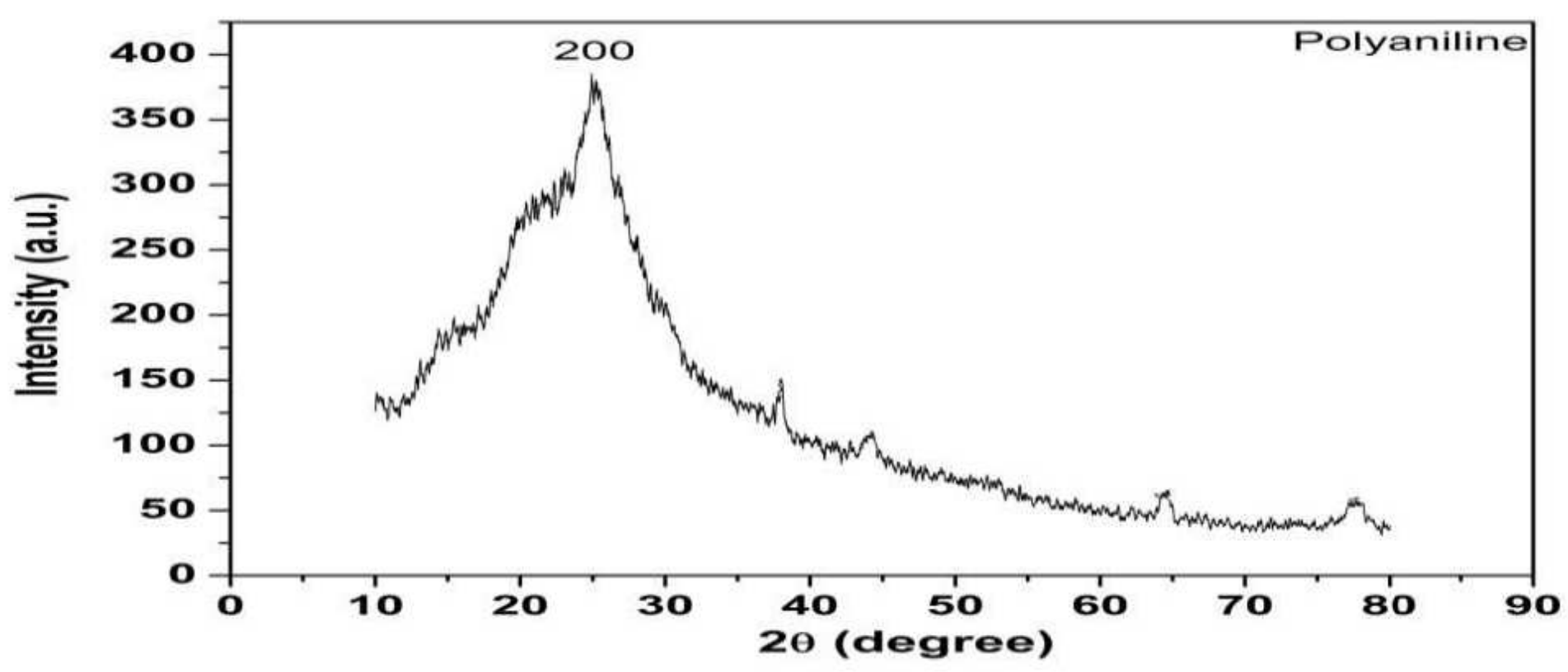

Figure 1

XRD pattern of Pure PANI

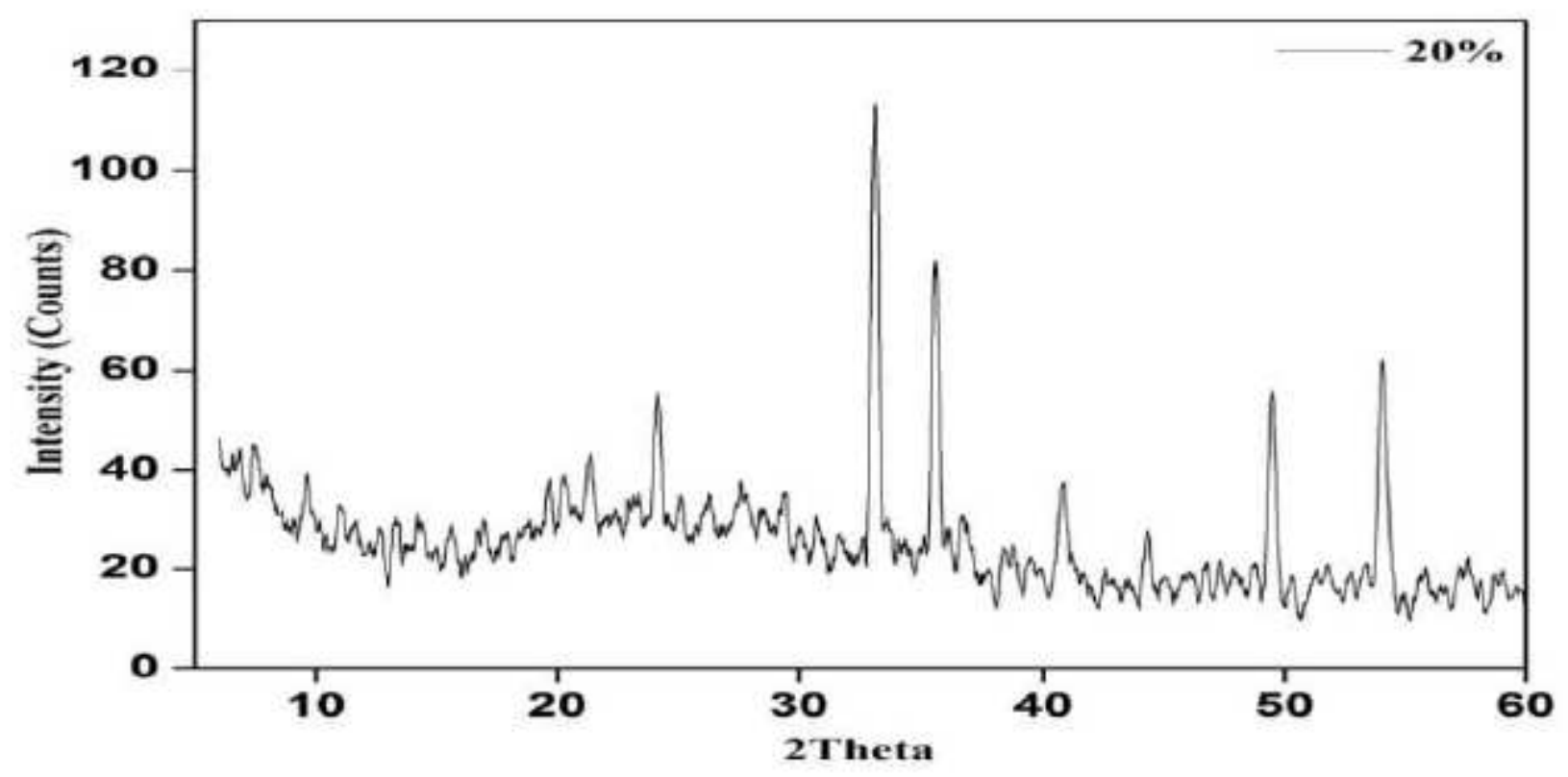

Figure 2

shows the X-ray diffraction pattern of PANI - MgO composite with $20 \mathrm{wt} \%$ 


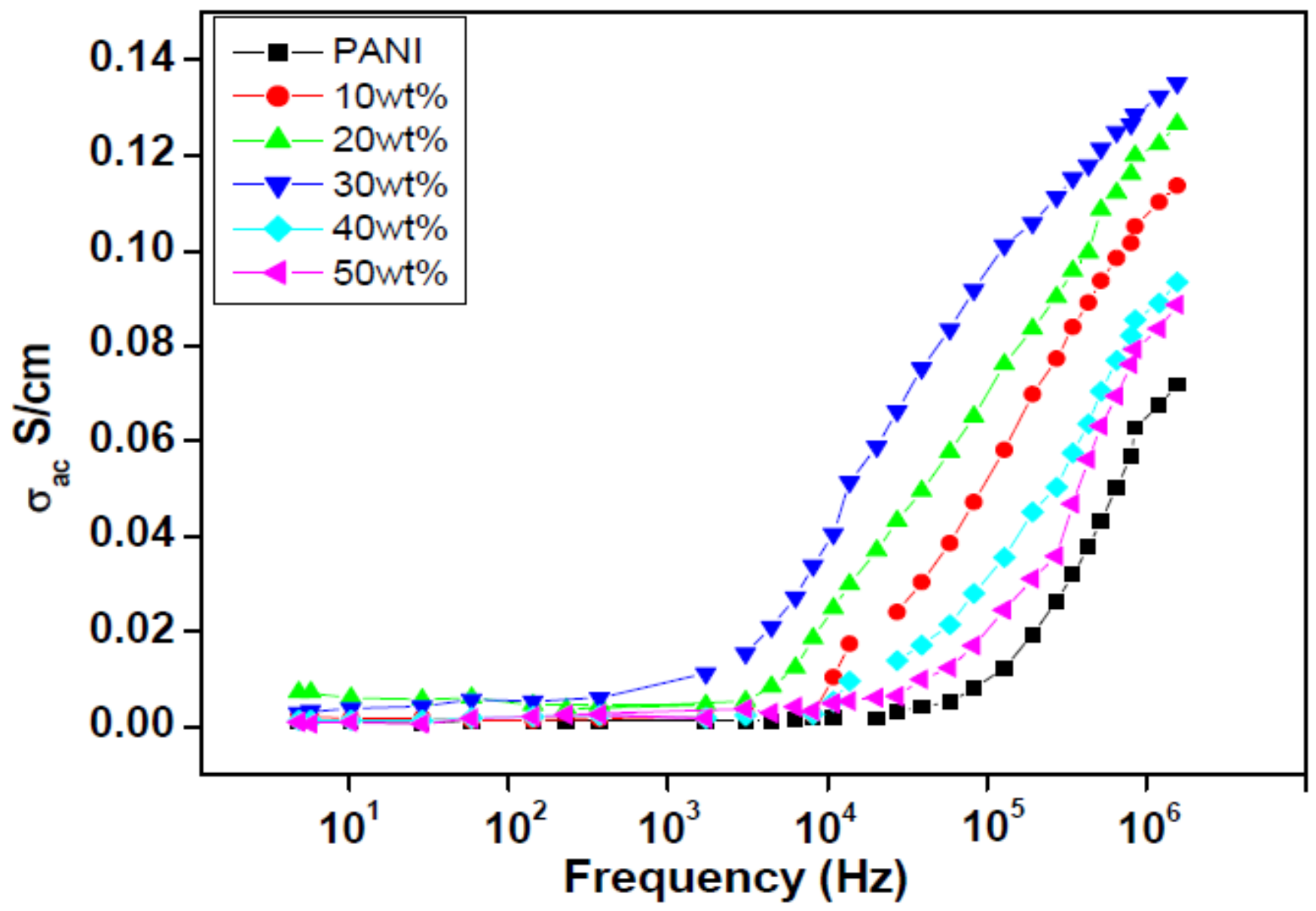

Figure 3

Variation of oac as a function of frequency for PANI-MgO

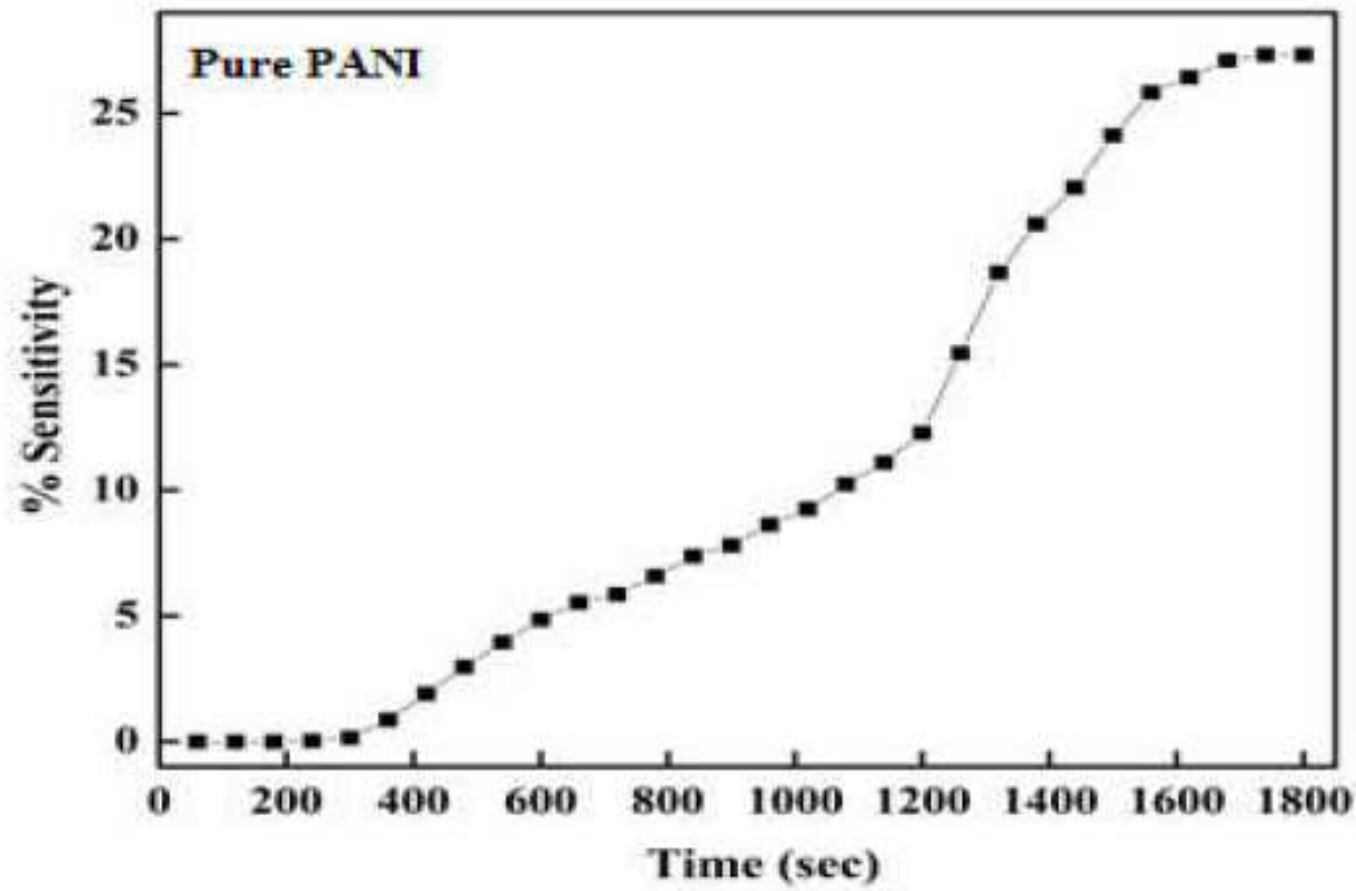


Figure 4

difference of sensitivities versus time for pure PANI

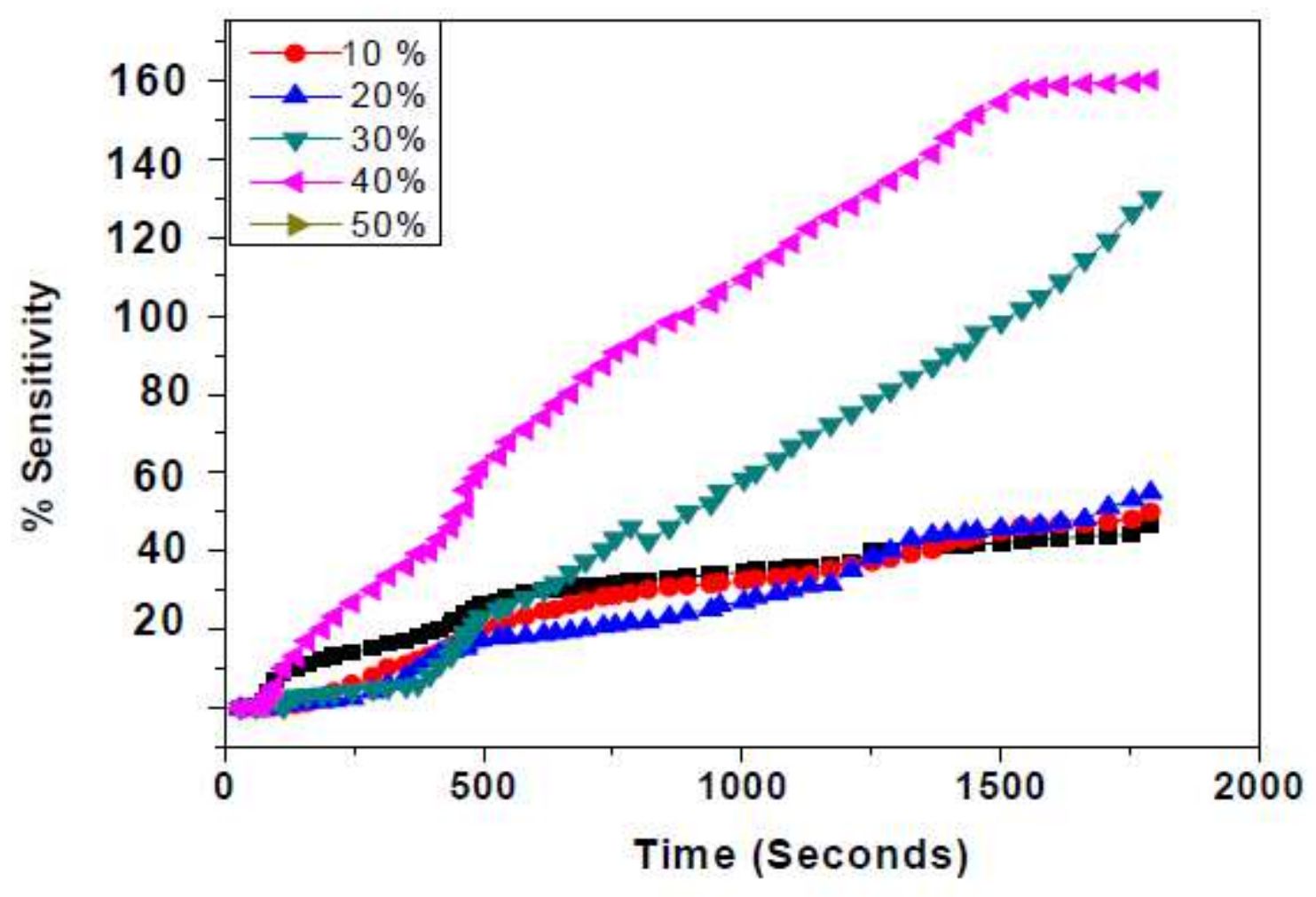

Figure 5

difference of sensitivities next to time for PANI-MgO 